\title{
A Diagnostic Analytics of Harmonic Source Signature Recognition by Using Periodogram
}

\author{
M.H. Jopri' ${ }^{1}$, A.R. Abdullah ${ }^{2}$, T. Sutikno ${ }^{3}$, M. Manap ${ }^{4}$, M.R. Ab Ghani ${ }^{5}$, A.S. Hussin ${ }^{6}$ \\ ${ }^{1,4}$ Center for Robotics and Industrial Automation (CeRIA), Faculty of Engineering Technology, \\ Universiti Teknikal Malaysia, Malaysia \\ ${ }^{2,5,6}$ CeRIA, Faculty of Electrical Engineering, Universiti Teknikal Malaysia, Malaysia \\ ${ }^{3}$ Department of Electrical Engineering, Universitas Ahmad Dahlan (UAD), Indonesia
}

\section{Article Info \\ Article history: \\ Received Jun 9, 2018 \\ Revised Jul 14, 2018 \\ Accepted Jul 30, 2018 \\ Keyword: \\ Diagnostic analytic \\ Harmonic source \\ Signature analysis \\ Signature recognition \\ Periodogram}

\begin{abstract}
This paper presents a diagnostic analytics of harmonic source signature recognition of rectifier and inverter-based load in the distribution system with single-point measurement at the point of common coupling by utilizing Periodogram. Signature recognition pattern is used to distinguish the harmonic sources accurately by obtaining the distribution of harmonic and interharmonic components and the harmonic contribution changes. This is achieved by using the significant signature recognition of harmonic producing load obtained from analysing the harmonic contribution changes. Based on voltage and current signature analysis, the distribution of harmonic components can be divided into three zones. To distinguish between the harmonic producing loads, the harmonic components are observed at these zones to get the signature recognition pattern. The result demonstrate that periodogram technique accurately diagnose and distinguish the type of harmonic sources in the distribution system
\end{abstract}

Copyright $\odot 2018$ Institute of Advanced Engineering and Science. All rights reserved.

\section{Corresponding Author:}

M. H. Jopri,

Advanced Digital Signal Processing Group, Faculty of Electrical Engineering,

Universiti Teknikal Malaysia Melaka, Hang Tuah Jaya,

76100 Durian Tunggal, Melaka, Malaysia

Email: hatta@utem.edu.my

\section{INTRODUCTION}

The increased and widespread use of the distributed harmonic sources in power system is leading to quantifying the individual harmonic impacts of the multiple harmonic producing loads. These harmonic sources are caused by nonlinear loads that are attached to the power system and are generally undesirable. The ability to maintain voltage and current signals with constant amplitude and constant fundamental frequency presents the quality of electrical power supplied to the customers. The limitation of harmonics pollution present at the point of common coupling (PCC) had been control by IEEE Std. 519 to improve the power quality which is widely accepted in industry [1]-[3]. The interaction between harmonic sources and the ac power supply can result in above allowable levels of harmonic distortion, overheating of motor and transformers, overloading of phase and neutral conductors in branch distribution circuits or interfering the operation of sensitive electronic equipment [4], [5]. This poses a potential threat to the regular performance of power system. Identifying the source of the harmonic distortion is not simply by just looking at the waveforms. Developing an accurate method and technique for identification of harmonic sources is required to remove this problem efficiently, especially when there is harmonic problem in a system, and improves the power quality management. Several methodologies were proposed over the years for detecting and identifying the harmonic source location and contributions [6]. However, the conventional techniques that are currently used for power quality monitoring are based on visual of voltage and current waveforms [7], [8]. 
Signal processing techniques have been widely used for automatic power quality disturbances detection and classification [9]. The most widely adopted approach in signal processing is spectral analysis using Fourier analysis which is Fourier transform [10]. From the application of Discrete Fourier Transform (DFT), it is proposed in [11] a method to extract the amplitude and phase angle of currents but considering on the components of odd number only(from the fundamental up to $15^{\text {th }}$ harmonic order). It used models based on Artificial Neural Network (ANN) to develop an application for identification of loads present in the electrical system using both the amplitude and phase angle of the measured currents. Unfortunately, the parameter of the phase angle of the currents can compromise the harmonic source identification as shown by [12]. As a result, it is proposed in [13] a research on the method to identify harmonic sources using the amplitude of the measured current only. An attribute selector named Wrapper is combined with the DFT of current for the data pre-processing step to obtain the most relevant amplitudes of harmonic current orders. So, these selected amplitudes of harmonic currents are given as inputs to the intelligent system. Usually the selection of attributes by Wrapper provides better results, however, this highly performance comes with a high computational cost [14] due to the exhaustive search method.

In [15], it introduced a user friendly and easy-to-use tool, named "Harmo Sim," to predict and simulate the behavior of nonlinear loads. Users are able to use this tool to do a comparative study of several loads on their own data. It used graphical visualization of different parameters such as total harmonic distortion (THD), line current, power factor and crest cofactor. However, if the power system contains similar type of loads, their current harmonic spectra will be quite similar. Then it will be difficult to predict the correct harmonic loads in this cases when considering current harmonics only [16]. Therefore it is not always true that current spectra itself can able to identify the load specially the similar type of nonlinear loads. Following this context, to overcome this difficulty, the proposed method utilizes the voltage measurements in place of current measurement to identify the type of nonlinear load [17]. The voltage magnitude method can be used to detect the harmonic source, however the procedure is not practical because need to do switching test on the site [18]. In real time, accuracy, quick estimation and low cost are important and most of the previous studies do not take into account [19],[20]. Based on above discussion, the limitation of previous techniques can be overcome using periodogram.

This paper proposes high accuracy, fast estimation and costs efficient to identify and diagnose type of MHS in the distribution system with single-point measurement at the PCC by utilizing periodogram. The periodogram is a method to represent signals in time-frequency representation (TFR). The diagnostic analytics of MHS is achieved by analyze the voltage and current signals by using the periodogram. Furthermore, harmonic indicies such as instantaneous total harmonic distortion and instantaneous total nonharmonic distortion are used to differentiate the harmonic and interharmonic components in the signals. The voltage and current signature of each harmonic sources are analyzed by studying the harmonic contribution changes. Finally, the distinguishment of MHS can be obtained accurately by using the signature recognition pattern that been obtained from the distribution of harmonic and interharmonic components and the harmonic contribution changes.

\section{RESEARCH METHOD}

A common type of harmonic producing loads are selected and modelled in Simulink Matlab. Furthermore, the diagnostic analytics of HPL signature recognition is performed by utilizing the periodogram.

\subsection{Harmonic Producing Load}

A common source of harmonic currents in power systems such as power electronic converters. The harmonic-producing load can have fairly consistent harmonic current emission characteristics over time or each may present a widely-varying characteristic depending on the control of the device, the characteristics of the system, and other variables (IEEE 519-2014). The power electronics equipment, such as three-phase rectifiers and three-phase inverter with pulse width modulation (PWM) switching are widely used and lead to the disturbances of the utility and the end-user's equipment [21]-[23]. Thus, in order to identify the root cause and to mitigate the harmonic disturbance, diagnostic analytics of harmonic sources is necessary to do so.

\subsection{Periodogram}

A harmonic spectrum of non-linear loads power analyser which characterizes the behavior of harmonic sources to provide preliminary data on the severity of the distortion problem is widely employed by the utilities. The periodogram spectral represents the distribution of power signal over frequency and it is 
based on a Fourier series model of the data, that is, specifically designed for determining harmonic components in power signals [24], [25]. It can be formulated as equation 1.

$$
S_{v}(f)=\left|\frac{1}{T} \int_{-\frac{T}{2}}^{\frac{T}{2}} v(t) e^{-j 2 \pi f t} d t\right|^{2}
$$

Where, $S v(f)$ in frequency domain; $v(t)$ is voltage waveform; VDC is direct current voltage and $\frac{\Delta f}{2}$ is system frequency.

\subsection{Instantaneous Total Harmonic Distortion}

Total harmonic distortion, THD, is used to measure of how much harmonic content in a waveform [26],[27],[8]. The total harmonic distortion of a waveform is defined mathematically as equation 2.

$$
T H D(t)=\frac{\sqrt{\sum_{h=2}^{H} V_{h, r m s}(t)^{2}}}{V_{1 r m s(t)}}
$$

Where $V_{h, r m s}(t)$ is RMS harmonic voltage and $V_{h, r m s}(t)$ is RMS fundamental voltage.

\subsection{Instantaneous Total Non-Harmonic Distortion}

Besides harmonic, a signal also contains interharmonic components that are not multiple integer of the power system frequency [28],[29]. Referring to this as the total nonharmonic distortion, (TnHD), the expression in equation $3[30]$ :

$$
\operatorname{Tn} H D(t)=\frac{\sqrt{V_{r m s}(t)^{2}-\sum_{h=0}^{H} V_{h, r m s}(t)^{2}}}{V_{1 r m s}(t)}
$$

\subsection{Proposed Technique Implementation}

The execution of proposed technique can be realised as depicts in Figure 1 and Figure 2. Two types of common and widely used harmonic sources which are the three-phase rectifier and three-phase inverter with pulse width modulation (PWM) switching [31],[32] are used in this research.

Meanwhile, as shwown in Figure 3, the measurement data are analysed by using periodogram and frequency spectrum. Furthermore, the harmonic indices which are instantaneous total harmonic distortion, $T H D(t)$ and instantaneous total non-harmonic distortion, $\operatorname{Tn} H D(t)$ are calculated. The contribution changes and distribution of harmonic and interharmonic components are obtained from the diagnostic analytic process. Finally, the distinguishment of harmonic sources can be obtained by observing the signature recognition pattern.

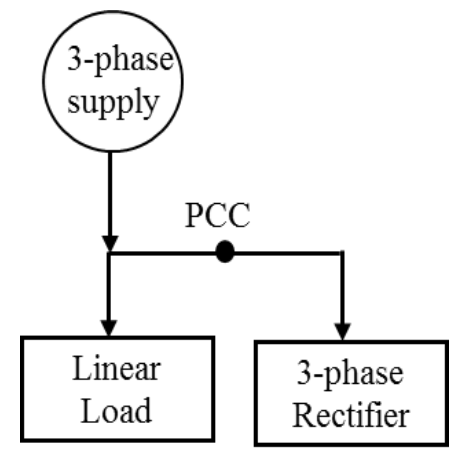

Figure 1. A rectifier-based load.

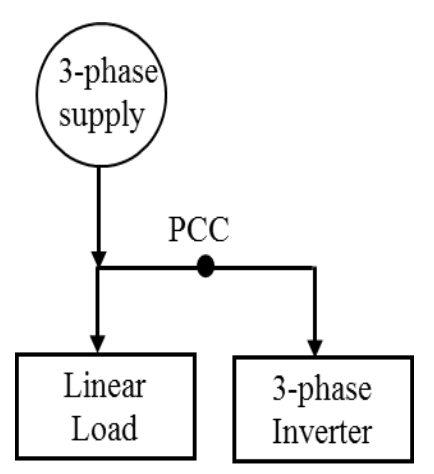

Figure 2. An inverter-based load. 


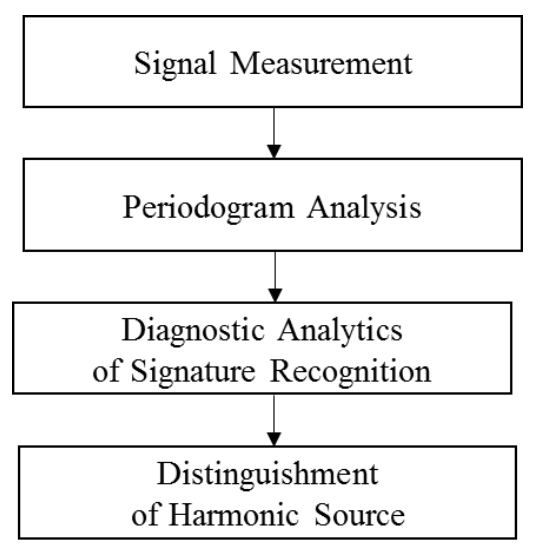

Figure 3. An implementation of harmonic source diagnostic analytics.

\section{RESULTS AND ANALYSIS}

The results of an analysis of harmonic indices, harmonic contribution changes and signature recognition pattern of harmonic sources which are rectifier-based load and inverter-based load presented in this section.

\subsection{Rectifier-based Load}

In this case study, the signature recognition of rectifier-based load is observed due to perform the harmonic source diagnostic. A six-pulses three-phase rectifier with Pulse Width Modulation (PWM) switching technique is selected to be the rectifier-based load. The voltage and current signal in time domain when this rectifier-based load utilized as the harmonic producing load shown in Figure 4(a). Clearly shown that the voltage and current signals are not a pure sinusoidal form. As shown in Figure 4(b), the harmonic indices which are $T H D(t)$ and $T n H D(t)$ in the range of $1.093 \%$ to $1.098 \%$ and $1.295 \%$ to $1.3 \%$, respectively. These harmonic indices show that the voltage signal consist of harmonic and interharmonic components. Nevertheless, the harmonic distortion level still in the permitted range of IEEE Standard 519-2014, where the total harmonic distortion cannot more than $8 \%$.

The current spectrum of signal shown in Figure 4(c). Whereas the harmonic current exist at $250 \mathrm{~Hz}$, $900 \mathrm{~Hz}$ and $1000 \mathrm{~Hz}$, respectively. In the meantime, the interharmonic components discovered at $375 \mathrm{~Hz}$, $425 \mathrm{~Hz}, 575 \mathrm{~Hz}$, and $675 \mathrm{~Hz}$, respectively. As this 6-pulses rectifier, the harmonic order start at $5^{\text {th }}$ while the $3^{\text {rd }}$ harmonic and below are eliminated. As shown in Figure 4(d), the voltage signal comprising four harmonic and two interharmonic components, individually. Next, to have a good understanding of converter-based load, a diagnostic analytic of converter-based load is performed and explain in next section.
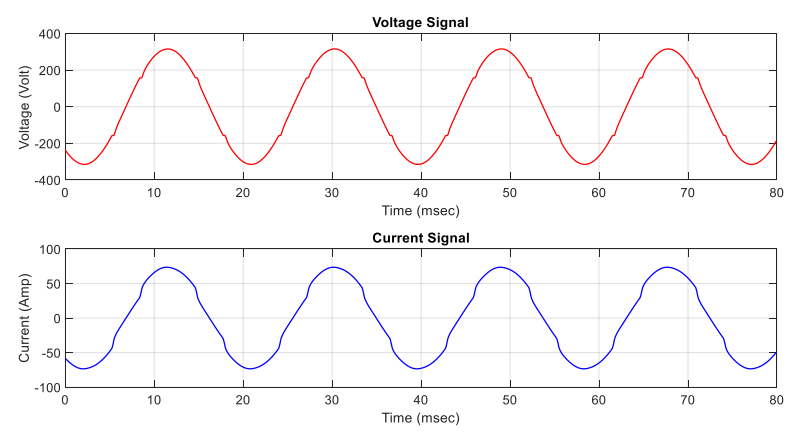

(a) 

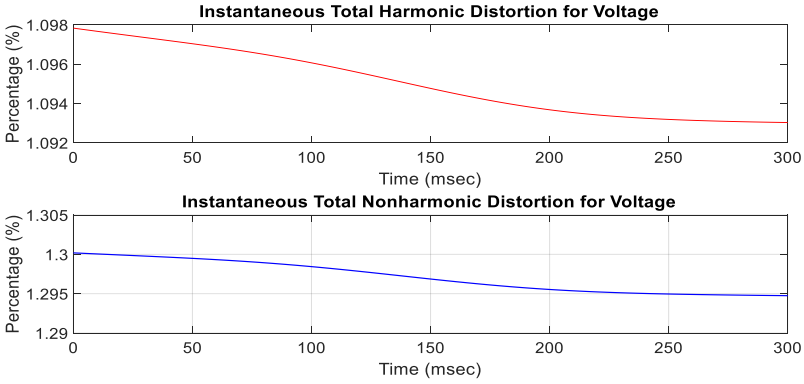

(b)

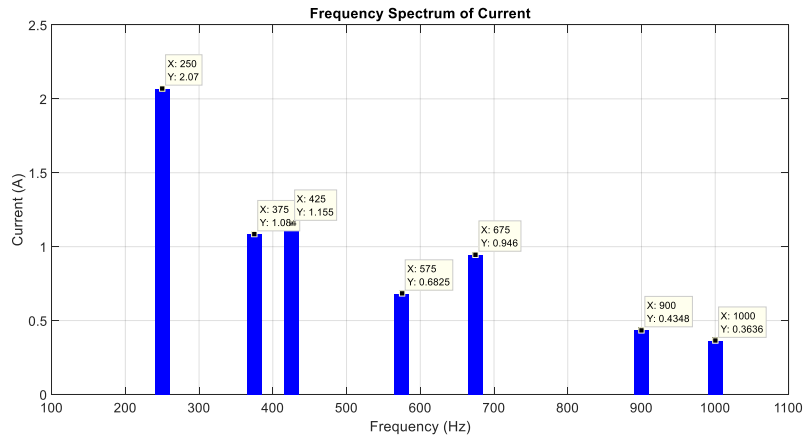

(c)

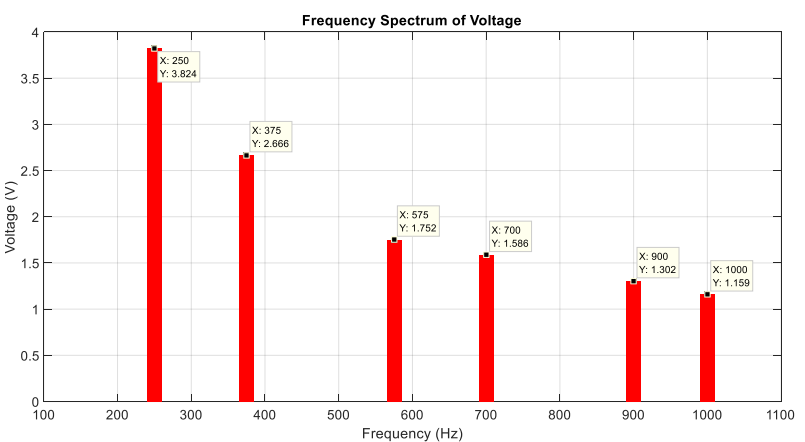

(d)

Figure 4. A Frequency Spectrum. a) A instantaneous voltage and current signal, b) $T H D(t)$ and $\operatorname{Tn} H D(t)$ of voltage signal, c) Frequency spectrum of harmonic and interharmonic of current signal, d) Frequency spectrum of harmonic and interharmonic of voltage signal.

\subsection{Converter-based Load}

This case study seeks to address the signature recognition of inverter-based load and the finding should make an important contribution to the harmonic source diagnostic. The three-phase AC-DC-AC converter with Pulse Width Modulation (PWM) switching technique was selected to be the inverter-based load. Figure 5(a) presents the voltage and current signal in time domain when the three-phase inverter was utilized as the harmonic producing load. Furthermore, Figure 5(b) show the harmonic indices which are $T H D(t)$ and $\operatorname{Tn} H D(t)$ in the range of $1.465 \%$ to $1.475 \%$ and $6.01 \%$ to $6.05 \%$, respectively. This harmonic indices show that the harmonic and interharmonic components are exist in the signal. However, the harmonic distortion level still in the permitted range of IEEE Standard 519-2014, where the total harmonic distortion cannot more than $8 \%$.

The spectrum of current drawn by the inverter shown in Figure 5(c). Whereby the harmonic current exist at $250 \mathrm{~Hz}, 350 \mathrm{~Hz}, 600 \mathrm{~Hz}, 900 \mathrm{~Hz}$ and $1000 \mathrm{~Hz}$, respectively. Meanwhile, the interharmonic components discovered at $575 \mathrm{~Hz}, 675 \mathrm{~Hz}$ and $875 \mathrm{~Hz}$, respectively. Figure 5(d) shows the frequency spectrum of voltage and it was distinguished four harmonic and six interharmonic components in the voltage signal, respectively. Previous analysis of harmonic and interharmonic contribution of rectifier-based load is done and further 
analysis on converter-based load is necessary due to conclude the hypothesis of signature recognition of HPL. In addition, no previous research distinguished the HPL based on harmonic and interharmonic contribution of voltage and current.
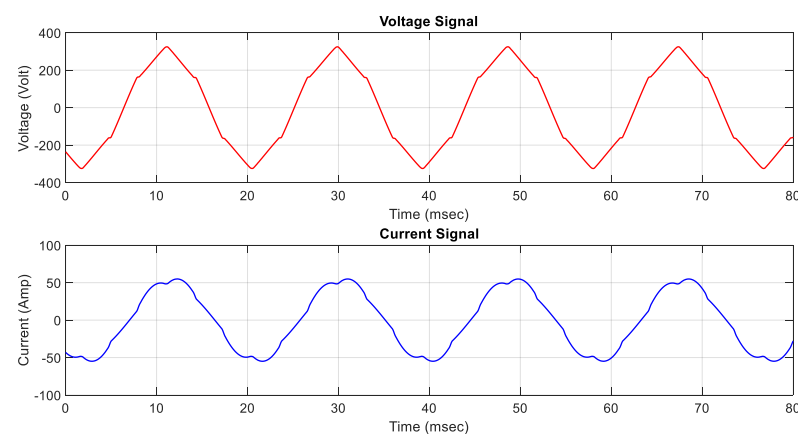

(a)
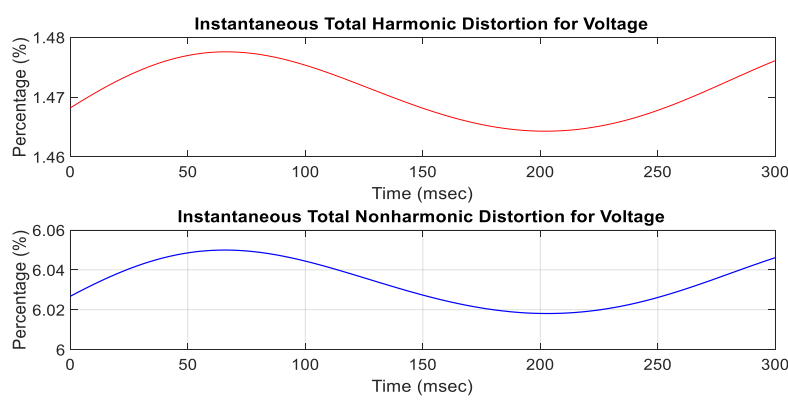

(b)

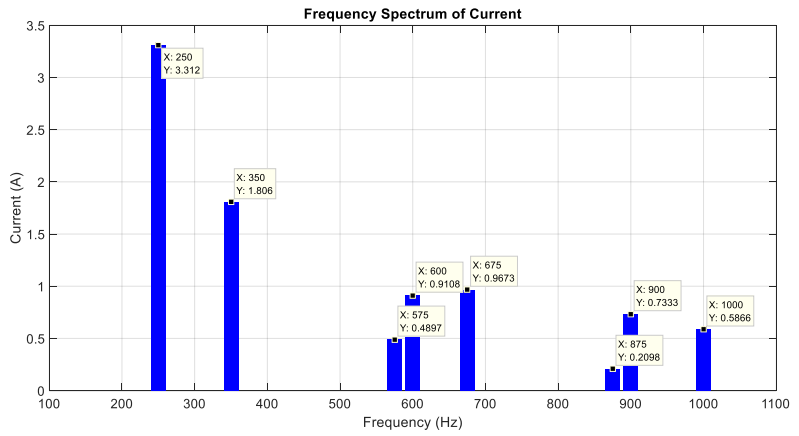

(c)

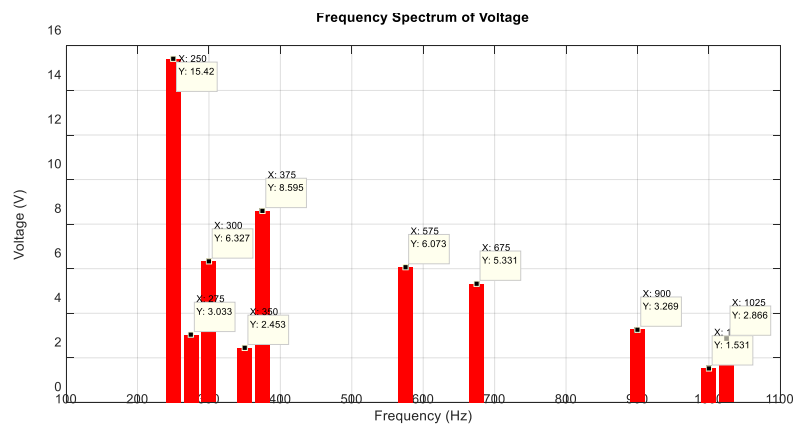

(d)

Figure 5. AC-DC-AC PWM converter a) A instantaneous voltage and current signal, b) $T H D(t)$ and $T n H D(t)$ of voltage signal, c) Frequency spectrum of harmonic and interharmonic of current signal, d) Frequency spectrum of harmonic and interharmonic of voltage signal. 


\subsection{Voltage and Current Signature Analysis}

Although extensive research has been carried out on harmonic source diagnostic, no single study exists which adequately study the relationship of contribution impact of harmonic and interharmonic and the HPL that in the power distribution system. The signature analysis of voltage and current is performed due to study the impact of the contribution to the system. Furthermore, this analysis enhance our understanding on voltage and current signature pattern towards the diagnostic analysis of HPLs. As shown in Figure 6, the harmonic contribution changes (HCC) clearly shows that the voltage contribution changes of converter-based load are dominant at most of frequencies comparing to the rectifier-based load. Interestingly, at $275 \mathrm{~Hz}$, $300 \mathrm{~Hz}, 350 \mathrm{~Hz}, 675 \mathrm{~Hz}$ and $1025 \mathrm{~Hz}$, only harmonic and interharmonic voltage components of converterbased load were exist with $100 \%$ rate of HCC. Turning now to the voltage signature of rectifier-based load that only has a dominant harmonic component at $700 \mathrm{~Hz}$ and $900 \mathrm{~Hz}$, respectively. Meanwhile at $700 \mathrm{~Hz}$, the HCC rate was $100 \%$. This paragraph has analysed the voltage signature, while the next paragraph will explain the analysis of current signature of HPLs.

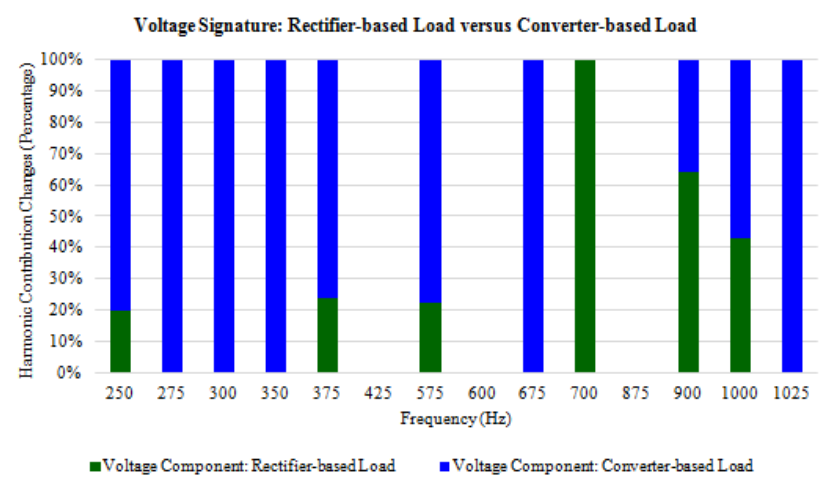

Figure 6. Voltage Signature Analysis.

What follows is an explanation of current signature of rectifier-based load and converter-based load. One of the signature component that contribute in the development of HPL's signature recognition is current signature. As shown in Figure 7, the most striking result to emerge from the result is that the HCC s of converter-based load have become so dominant. The HCC rate for converter-based load were $100 \%$ at $350 \mathrm{~Hz}, 600 \mathrm{~Hz}$ and $875 \mathrm{~Hz}$. These are: $250 \mathrm{~Hz}, 350 \mathrm{~Hz}, 600 \mathrm{~Hz}, 875 \mathrm{~Hz}, 900 \mathrm{~Hz}$ and $1000 \mathrm{~Hz}$. Comparing the current signature of converter-based load, it can be seen that the CCOTs for rectifier-based load with rate of $100 \%$ at $375 \mathrm{~Hz}$ and $425 \mathrm{~Hz}$. In the meantime, it was dominant too at $575 \mathrm{~Hz}$ and yielded a $58 \%$ of $\mathrm{HCC}$.

A strong relationship of voltage and current signature versus HCC is interesting because this significant relationship can be utilized in diagnostic the above said HPLs. In this section, it is explained that the HCC for voltage and current signature of converter-based load are so dominant compare to rectifier-based load.

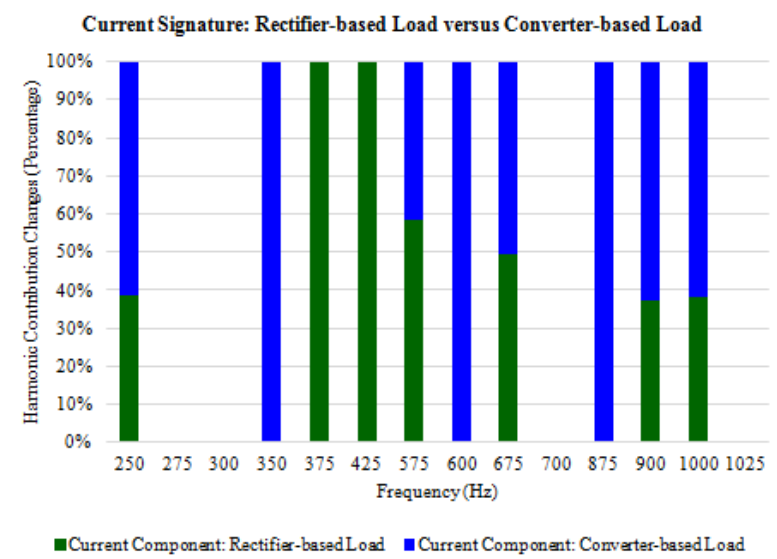

Figure 7. Current Signature Analysis. 


\subsection{Signature Recognition of Harmonic Producing Load}

The results obtained from the preliminary analysis were analyse and the significant recognition of harmonic producing load was obtained. With refer to the Figure 7, the distribution of harmonic components can be divided into three zones; zone $1(150 \mathrm{~Hz}$ to $450 \mathrm{~Hz})$, zone $2(450 \mathrm{~Hz}$ to $750 \mathrm{~Hz})$ and zone $3(750 \mathrm{~Hz}$ to $1050 \mathrm{~Hz})$. Furthermore, by tabulating the harmonic and interharmonic components as depicts in Figure 8, the most striking result to emerge from the data is in the zone 1 and zone 3 , the tabulation of harmonic and interharmonic components are higher in these zone. Whereby for inverter-based load, in zone 1, five voltage harmonic and 2 currents harmonic components were distinguished. In zone 2, three currents harmonic and two voltage harmonic components were distinguished in the signal. Furthermore, in zone 3, three voltage harmonic and three current harmonic components were detected in the signal, respectively. In the meantime, as shown in Figure 9, the signature recognition of rectifier-based load, each zone consist less harmonic components compare to the inverter-based load signature recognition. It can thus be suggested that the converter-based load produced more harmonic and interharmonic components at zone 1 and zone 3 compare to rectifier-based load. Thus, the diagnostic of HPLs successfully done by observing the signature recognition pattern at zone 1, zone 2 and zone 3 . The present results are significant in diagnosing the rectifier-based load and converter-based load that connected to the system.

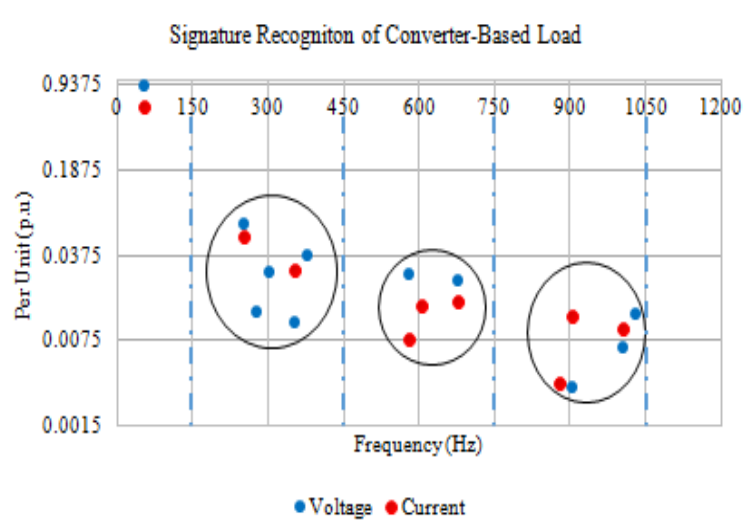

Figure 8. Signature Recognition of Converter-based Load.

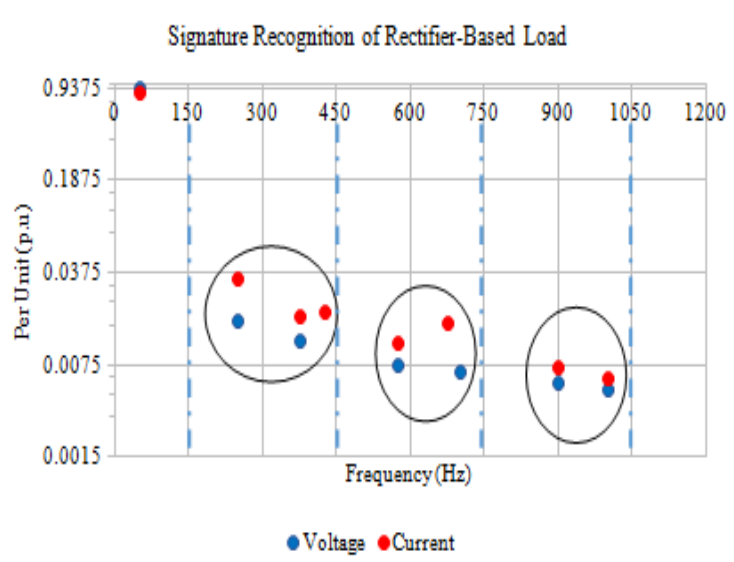

Figure 9. Signature Recognition of Rectifier-Based Load

\section{CONCLUSION}

The main concern of this research is to diagnose type of harmonic producing load which are connected in the distribution system and acted as harmonic sources by utilizing periodogram technique. The main contribution of this research is the signature recognition pattern of harmonic sources that can be used to distinguish type of harmonic sources. Two common and widely used of harmonic producing load which are three-phase rectifier and three-phase inverter are modelled and chosen in this research. Based on signature recoginiton pattern, both types of harmonic producing load can be distinguished plainly by observing the zone 1, zone 2 and zone 3 . The inverter-based load always has more harmonic components for each zone compare to the rectifier-based load type.

Consequently, considering the explanation, the periodogram technique accurately diagnosed and distinguished type of harmonic sources in the power distribution system.

\section{ACKNOWLEDGEMENTS}

This research is supported by Advanced Digital Signal Processing Laboratory (ADSP Lab). Special thanks also to the Faculty of Electrical Engineering and Faculty of Engineering Technology of Universiti Teknikal Malaysia Melaka (UTeM), Center for Robotics and Industrial Automation (CeRIA) of UTeM, Ministry of Higher Education Malaysia (MOHE) and Ministry of Science, Technology and Innovation (MOSTI) for giving their cooperation and funding for this research with grant number 06-01-14-SF00119 L00025. Their support is gratefully acknowledged. 


\section{REFERENCES}

[1] A. R. Abdullah, M. Manap, M. R. Yusoff, and T. Sutikno, "A fast localization of multiple harmonic sources for rectifier loads by utilizing periodogram," Telkomnika (Telecommunication Comput. Electron. Control., vol. 15, no. $1,2017$.

[2] M. H. Jopri, A. R. Abdullah, M. Manap, M. R. Yusoff, T. Sutikno, and M. F. Habban, "An improved detection and classification technique of harmonic signals in power distribution by utilizing spectrogram," Int. J. Electr. Comput. Eng., vol. 7, no. 1, 2017.

[3] IEEE, IEEE Recommended Practices and Requirements for Harmonic Control in Electrical Power Systems. 1993.

[4] S. M. Nawi, J. Johari, and A. F. Abidin, "A fuzzy logic application for identification of harmonics disturbances sources," Natl. Power Eng. Conf. PECon 2003 - Proc., pp. 27-31, 2003.

[5] M. H. Abdullah, A.R.; Norddin, N.; Abidin, N.Q.Z., "Leakage current analysis on polymeric and non-polymeric insulating materials using time-frequency distribution," Power Energy (PECon), 2012 IEEE Int. Conf., no. December, pp. 2-5, 2012.

[6] A. Abdullah, M. Jopri, and M. Manap, "An Improved Spectrogram to Identify Multiple Harmonic Sources in Distribution System with Inverter Loads," Proc., vol. 7, no. 4, pp. 1355-1365, 2017.

[7] N. H. T. Huda, A. R. Abdullah, and M. H. Jopri, "Power quality signals detection using S-transform," in Proceedings of the 2013 IEEE 7th International Power Engineering and Optimization Conference, PEOCO 2013, 2013.

[8] A. R. Abdullah, N. S. Ahmad, N. Bahari, M. Manap, A. Jidin, "Short-circuit switches fault analysis of voltage source inverter using spectrogram,” Electr. Mach. Syst. (ICEMS), 2013 Int. Conf., pp. 1808-1813, 2013.

[9] A. Rahim Abdullah, N. H. T. H. Ahmad, N. a. Abidullah, N. H. Shamsudin, "Performance Evaluation of Real Power Quality Disturbances Analysis Using S-Transform,” Appl. Mech. Mater., vol. 752-753, pp. 1343-1348, 2015.

[10] N. H. H. and Abidullah, N. A, Abdullah, A. R., Zuri_Sha'ameri, A., Shamsudin, N.H., Ahmad, "Real-Time Power Quality Disturbances Detection and Classification System," World Appl. Sci. J., vol. 32, no. 8, pp. 16371651,2014

[11] D. Srinivasan, W. S. Ng, and A. C. Liew, "Neural-Network-Based Signature Recognition for Harmonic Source Identification," IEEE Trans. Power Deliv., vol. 21, no. 1, pp. 398-405, Jan. 2006.

[12] S. Varadan and E. B. Makram, "Practical considerations in the application of neural networks to the identification of harmonic loads," Electr. Power Syst. Res., vol. 30, no. 2, pp. 103-106, 1994.

[13] R. A. S. Fernandes, S. M. Ranzini, I. N. Silva, and M. Oleskovicz, "Wrapper attribute selector and intelligent systems applied to the identification of residential harmonic sources," IEEE Power Energy Soc. Gen. Meet., 2012.

[14] M. A. Hall and G. Holmes, "Benchmarking Attribute Selection Techniques for Discrete Class Data Mining," IEEE Trans. Knowl. Data Eng., vol. 15, no. 6, pp. 1437-1447, 2003.

[15] J. Baptista, R. Morais, A. Valente, S. Soares, M. Candeias, and M. J. C. S. Reis, "HarmoSim: A tool for harmonic distortion simulation and assessment of nonlinear loads," Comput. Appl. Eng. Educ., vol. 22, no. 2, pp. 340-348, 2014

[16] D. Saxena, K. Verma, and S. Singh, "Power quality event classification: an overview and key issues," Int. J. Eng. Sci. Technol., vol. 2, no. 3, pp. 186-199, 2010.

[17] a. Banshwar and a. K. Chandel, "Identification of harmonic sources using fuzzy logic," $2010 \mathrm{Jt}$. Int. Conf. Power Electron. Drives Energy Syst. 2010 Power India, pp. 1-7, 2010.

[18] M. H. Jopri, N. A. Abidullah, G. Z. Peng, and A. R. Abdullah, "A new two points method for identify dominant harmonic disturbance using frequency and phase spectrogram," Int. Rev. Electr. Eng., vol. 9, no. 2, pp. 453-459, 2014.

[19] A. Abdullah, M. Jopri, and M. Manap, “An Improved Spectrogram to Identify Multiple Harmonic Sources in Distribution System with Inverter Loads," Proc., vol. 7, no. 4, p. 11591, 2017.

[20] P. Supriya and T. N. Padmanabhan Nambiar, "Review of harmonic source identification techniques," Int. Rev. Electr. Eng., vol. 7, no. 3, pp. 4525-4531, 2012.

[21] J. Afsharian, D. D. Xu, B. Wu, B. Gong, and Z. Yang, "The Optimal PWM Modulation and Commutation Scheme for Three-Phase Isolated Buck Matrix Type Rectifier," IEEE Trans. Power Electron., vol. 8993, no. c, pp. 1-1, 2017.

[22] S. Somkun, "Fast DC Bus Voltage Control of Single-Phase PWM Rectifiers using A Ripple Voltage Estimator," pp. 0-5, 2016.

[23] T. F. P. W. M. R. Under, "Modeling, Modulation, and Control of the Three-Phase Four-Switch PWM Rectifier Under Balanced Voltage," IEEE Trans. Power Electron., vol. 31, no. 7, pp. 4892-4905, 2016.

[24] M. H. Jopri, A. R. Abdullah, N. M. Kassim, M. Manap, N. A. Ngatiman, and M. R. Yusoff, "Localization of Multiple Harmonic Sources for Inverter Loads Utilizing Periodogram," J. Teknol., vol. 8, no. 2, pp. 87-91, 2016.

[25] M. Z. R. Zuber Ahmadi, A. Jidin, K. B. Jaffar, M. N. Othman, R. N. P. Nagarajan, "Minimization of torque ripple utilizing by 3-L CHMI in DTC," Proc. 2013 IEEE 7th Int. Power Eng. Optim. Conf. PEOCO 2013, no. June, pp. 636-640, 2013.

[26] A. R. Abdullah, M. Manap, M. F. Habban, and T. Sutikno, "An accurate classification method of harmonic signals in power distribution system by utilising S-transform," Telkomnika (Telecommunication Comput. Electron. Control., vol. 15, no. 1, 2017.

[27] A. R. Abdullah, N. A. Abidullah, N. H. Shamsudin, N. H. H. Ahmad, "Power quality signals classification 
system using time-frequency distribution", vol. 494-495. 2014.

[28] M. Jopri, A. Abdullah, T. Sutikno, and M. Manap, "A Utilisation of Improved Gabor Transform for Harmonic Signals Detection and Classification Analysis,” Int. J., vol. 7, no. 1, pp. 21-28, 2017.

[29] N. A. Abidullah, A. R. Abdullah, N. H. Shamsudin, N. H. T. H. Ahmad, "Real-time power quality signals monitoring system," Proceeding - 2013 IEEE Student Conf. Res. Dev. SCOReD 2013, no. December, pp. 433438, 2015.

[30] A. R. Abdullah, G. Z. Peng, S. A. Ghani, and M. H. Jopri, "A new vector draft method for harmonic source detection at point of common coupling," Proc. 2014 IEEE 8th Int. Power Eng. Optim. Conf. PEOCO 2014, no. March, pp. 110-114, 2014.

[31] K. B. Nagasai and T. R. Jyothsna, "Harmonic Analysis and Application of PWM Techniques for Three Phase Inverter,” Int. Res. J. Eng. Technol., pp. 1228-1233, 2016.

[32] L. R. L. V. Raj, A. Jidin, K. Abdul Karim, T. Sutikno, R. Sundram, "Improved torque control performance of direct torque control for 5-phase induction machine," Int. J. Power Electron. Drive Syst., vol. 3, no. 4, 2013.

\section{BIOGRAPHIES OF AUTHORS}

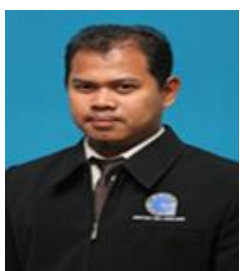

Mohd Hatta Jopri was born in Johor, Malaysia on 1978. He received his B.Sc from Universiti Teknologi Malaysia in 2000 and Msc. in Electrical Power Engineering from RheinischWestfälische Technische Hochschule Aachen (RWTH), Germany in 2011. Since 2005, he has been an academia staff in the Universiti Teknikal Malaysia Melaka (UTeM) and currently he pursuing his $\mathrm{PhD}$ in the area of power quality.

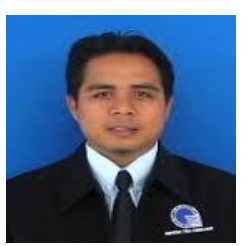

Abdul Rahim Abdullah, PhD was born in Kedah, Malaysia on 1979. He received his B. Eng., Master Eng., PhD Degree from Universiti Teknologi Malaysia in 2001, 2004 and 2011 in Electrical Engineering and Digital Signal Processing, respectively. He is currently an Associate Professor with the Department of Electrical Engineering, Chief of Advanced Digital Signal Processing (ADSP) Lab and Center of Excellent (COE) Chief for Universiti Teknikal Malaysia Melaka (UTeM).

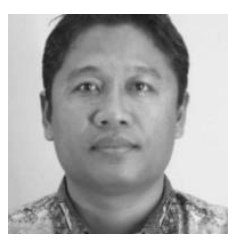

Tole Sutikno is an Associated Professor in Department of Electrical Engineering at Universitas Ahmad Dahlan (UAD), Indonesia. He has completed his studies for B.Eng., M.Eng., Ph.D. in Electrical Engineering from Diponegoro University, Gadjah Mada University and Universiti Teknologi Malaysia, respectively. His research interests include the field of industrial electronics and informatics, power electronics, FPGA applications, embedded systems, data mining, information technology and digital library.

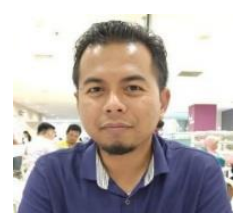

Mustafa Manap was born in Kuala Lumpur, Malaysia on 1978. He received his B.Sc from Universiti Technologi Malaysia in 2000 and Msc. in Electrical Engineering from Universiti Teknikal Malaysia Melaka (UTeM) 2016. Since 2006, he has been an academia staff in the Universiti Teknikal Malaysia Melaka (UTeM). His research interests are power electronics and drive, instrumentation, and DSP application.

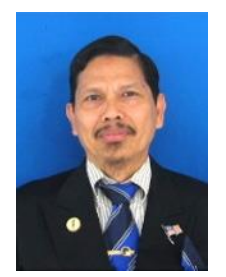

Datuk Dr. Mohd. Ruddin Ab. Ghani currently a Professor of Electrical Engineering with the Faculty of Electrical Engineering, Universiti Teknikal Malaysia Melaka (UTeM). His research interest are system engineering, energy control and distribution automation.

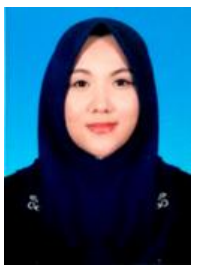

Adibah Syahirah Hussin was born in Johor, Malaysia on 1990. She received her B.Eng in Electrical Engineering from Dalhousie University Canada in 2014. She has worked in Texas Instruments Electronics Malaysia as Test Engineer since 2014. Currently, she is a master degree student researcher in power quality in Electrical Engineering at Universiti Teknikal Malaysia Melaka (UTeM). 